\title{
Does Being a Refugee Increase the Possibility of Complicated Appendicitis?
}

\author{
Durmuş Ali Çetin 1, ${ }^{1}$, Mehmet Patmano², Tufan Gümüş ${ }^{2}$ and Hasan Elkan² \\ 1 MD, University of Health Sciences, Tepecik Training and Research Hospital, Department of General Surgery, İzmir, Turkey \\ 2 MD, Şanlıurfa Training and Research Hospital, Department of General Surgery, Şanlıurfa, Turkey
}

* Corresponding author: Durmuş Ali Çetin, University of Health Sciences, Tepecik Training and Research Hospital, Department of General Surgery, İzmir, Turkey. Tel: +905054378667; Email: drdurmusalicetin@gmail.com

Received 2021 February 22; Revised 2021 August 20; Accepted 2021 August 29

\begin{abstract}
Background: Refugees may have problems in recognizing their illnesses and accessing treatment due to communication and sociocultural factors.

Objectives: This study aimed to present whether there was a difference in complicated appendicitis rates between Turkish and refugee patients.

Methods: A total of 563 patients who underwent appendectomy surgery in our ho spital between September 2018 and June 2020 and met the study criteria were examined in this study. The patients were divided into two groups of Turkish (Group 1) and refugee (Group 2) patients. The demographic, clinical, and histopathological characteristics of the patients were compared in this study.

Results: Groups 1 and 2 consisted of 489 (86.9\%) and 74 (13.1\%) patients, respectively. Moreover, there were 278 (56.9\%) and 36 (48.6\%) male patients in Groups 1 and 2, respectively. The median age of all patients was obtained at 28 (age range: 18-81 years), and the median (interquartile range ages of the Turkish and refugee patients were estimated at 28 (age range: 23 -36) and 27 (age range 21-36) years, respectively. Perforated appendix detection rate, open appendectomy ratio, preoperative C-reactive protein level, histopathological gangrenous or perforated appendicitis ratio, and postoperative hospital stay length were found higher in the refugee patients $(\mathrm{P}<0.05)$.

Conclusion: Refugee patients are intense in countries, such as Turkey. It is believed that general surgery specialists should consider the possibility of complicated appendicitis in refugee patients scheduled for surgery for acute appendicitis.
\end{abstract}

Keywords: Acute appendicitis, Appendectomy, Complicated appendicitis, Perforation, Refugee

\section{Background}

Acute appendicitis is the most common cause of acute abdomen with a lifetime prevalence of around $7 \%$ (1). In the diagnosis of acute appendicitis, laboratory examinations, radiological imaging methods, anamnesis, and physical examination are used. The critical fact in acute appendicitis is to achieve a definite diagnosis and perform surgery at the right time before complications develop. Appendix perforation is the most important complication of acute appendicitis. The clinical presentation of acute appendicitis has various complaints, which can lead to a delay in diagnosis that increases the perforation probability. Perforation, which increases the risk of abscess formation, wound infection, and sepsis, is an important cause of morbidity and mortality. In this regard, the most important factor is delays due to patient-related causes or diagnostic difficulties. For this, many studies have been conducted on imaging methods, scoring systems, and laboratory markers (2-7). The number of Syrian refugees in Turkey is higher than that in other neighboring countries. Refugees in Turkey and around the world come across challenging living conditions. They experience many physical and psychological health problems. The health services in Turkey are provided free of charge by community clinics and public hospitals for all Syrian refugees. However, due to some factors, such as the effects of changing life conditions, unfavorable socio-economic conditions, and communication problems (language barrier), refugee patients may delay their hospital applications. Furthermore, the refugees' admission process may be delayed in emergency cases due to changing life conditions.

\section{Objectives}

This study aimed to present the demographic, clinical, and histopathological characteristics of Turkish and refugee patients who underwent appendectomy due to acute appendicitis and find whether there was a difference between these groups in terms of complicated appendicitis rates.

\section{Methods}

\subsection{Study design and patients}

The records of patients who underwent open or laparoscopic appendectomy for acute appendicitis 
at the Şanlıurfa Training and Research Hospital General Surgery Clinic between September 2018 and June 2020 were reviewed retrospectively. The study was conducted under the Helsinki Declaration's rules after obtaining the approval of the Ethics Committee (HRU/20.11.04). Informed consent was obtained from all patients before surgery. Patients who had an incidental appendectomy and elective appendectomy, as well as those under the age of 15 years, along with pregnant patients and those with severe comorbidity, and the patients with missing data in the hospital database were excluded from the study. Therefore, a total of 563 patients who met the study criteria were included in the study. The patients were then divided into two groups according to their nationalities, including Turkish (Group 1) and refugee (Group 2) patients.

\subsection{Data}

Age, gender, preoperative laboratory values, performed surgery type, presence of appendix perforation, duration of postoperative hospital stay were recorded in this study. White blood cell count (WBC), hematocrit, neutrophil, lymphocyte, platelet, mean platelet volume, red cell distribution of width, C-reactive protein (CRP), bilirubin, aspartate aminotransferase, alanine aminotransferase, and albumin were also analyzed in this study. Neutrophil/lymphocyte (NLR) and platelet/ lymphocyte ratios were calculated based on complete blood counts, and histopathological characteristics were recorded from the hospital computer database.

\subsection{Statistical Analysis}

The obtained data were analyzed in SPSS software (Statistical Package for the Social Sciences; version 25 Inc., Chicago, IL, USA), and the results were expressed as mean $\pm \mathrm{SD}$, median (interquartile range [IQR]) values, and a percentage where necessary. The Kolmogorov-Smirnov test was used to examine the distribution of the collected data. Data with normal distribution were analyzed using the Student t-test. In addition, the group analysis of non-parametric data was performed with the Mann-Whitney U test, and the categorical groups were compared employing the Chi-square test. A p-value less than 0.05 was considered statistically significant.

\section{Results}

A total of 563 patients who met the study criteria were included in this study and divided into Turkish(Group 1; $\mathrm{n}=489 ; 86.9 \%$ ) and refugee patients (Group 2; $n=74 ; 13.1 \%$ ). The median age of all patients was estimated at 28 (age range: 18-81 years), and the median IQR ages of Turkish and refugee patients were obtained at 28 (age range: 23-36) and 27 (age range: 21-36) years, respectively. The majority of the patients in the Turkish and refugee groups were male (There were $278(56.9 \%)$ and $36(48.6 \%)$ male patients in Turkish and refugee patients, respectively.) The preoperative median IQR of CRP in the refugee patient group was $37 \mathrm{mg} / \mathrm{L}(5-94.5)$ that was significantly higher than that in the Turkish group (12.9 mg/L (3-41), P=0.001). Other laboratory parameters were similar for both groups. In the Turkish patient group, 391 (80\%) and 98 (20\%) patients underwent open and laparoscopic appendectomy, respectively. In the refugee patient group, $67(90.5 \%)$ and 7 (9.5\%) patients underwent open and laparoscopic appendectomy, respectively. The laparoscopic appendectomy rate was higher in the Turkish patient group $(\mathrm{P}=0.029)$. After comparing the presence of appendix perforation between the two groups, perforation was found in $67(13.7 \%)$ cases of the Turkish patient group. The number of non-complicated appendicitis was obtained at $422(86.3 \%)$ cases. On the other hand, perforation was detected in 24 $(32.4 \%)$ cases in the refugee patient group, and the number of non-complicated appendicitis was estimated at $50(67.6 \%)$ patients. The perforated appendix rate was higher in the refugee patient group $(\mathrm{P}<0.001)$. The total perforated appendix rate was obtained at $16.2 \%(91 / 563)$. Furthermore, the postoperative histopathological characteristics of both patient groups were examined. In the Turkish patient group, normal appendices, acute appendicitis (acute appendicitis or acute phlegmonous appendicitis), perforated or gangrenous appendicitis, and appendix tumour were observed in 20 (4.1\%), 424 (86.7\%), 41 $(8.4 \%)$, and $4(0.9 \%)$ patients, respectively. On the other hand, in the refugee patient group, $3(4.1 \%)$, $49(66.2 \%), 21(28.4 \%)$, and $1(1.4 \%)$ patients had normal appendices, acute appendicitis (acute appendicitis or acute phlegmonous appendicitis), perforated or gangrenous appendicitis, and appendix tumour, respectively. In the refugee patient group, the histopathologically perforated or gangrenous appendicitis rate was higher, and this finding was statistically significant $(\mathrm{P}<0.001)$. The median IQR of postoperative hospital stay lengths in the Turkish patient group and the refugee patient group were obtained at 2 (range: 1-2) and 2 (range: 1-5) days, respectively. Postoperative hospital stay was statistically significant in the refugee patient group $(\mathrm{P}=0.004)$. The demographic, clinical, laboratory, and histopathological characteristics of the patients are summarized in Table 1. 
Table 1. Demographic, clinical, laboratory, and histopathological characteristics of the patients

\begin{tabular}{|c|c|c|c|c|}
\hline Variables & & $\begin{array}{c}\text { Group-1 } \\
\text { (Turkish patients) } \\
\text { (n=489, 86.9\%) }\end{array}$ & $\begin{array}{c}\text { Group-2 } \\
\text { (Refugee patients) } \\
(\mathrm{n}=\mathbf{7 4 , 1 3 . 1 \% )}\end{array}$ & P-value \\
\hline Age (year) & & $28(23-36)$ & $27(21-36)$ & $0.429^{*}$ \\
\hline Gender & $\begin{array}{l}\text { Male } \\
\text { Female }\end{array}$ & $\begin{array}{l}278(56.9 \%) \\
211(43.1 \%)\end{array}$ & $\begin{array}{l}36(48.6 \%) \\
38(51.4 \%)\end{array}$ & $0.186^{* *}$ \\
\hline \multirow{14}{*}{$\begin{array}{l}\text { Preoperative laboratory } \\
\text { values }\end{array}$} & WBC $\left(x 10^{3} / \mu \mathrm{l}\right)$ & $13.6 \pm 4.04$ & $13.3 \pm 4.12$ & $0.556^{* * *}$ \\
\hline & Htc (\%) & $41.1(37.2-44.5)$ & 39.9 (37.07-44.72) & $0.871^{*}$ \\
\hline & Neutrophil $\left(\mathrm{x} 10^{3} / \mu \mathrm{l}\right)$ & $10.2(7-13)$ & $9.25(6.62-12.05)$ & $0.368^{*}$ \\
\hline & Lymphocyte $\left(x 10^{3} / \mu \mathrm{l}\right)$ & $2(1.5-2.6)$ & $2.1(1.3-2.52)$ & $0.730^{*}$ \\
\hline & Platelet $\left(\mathrm{x} 10^{3} / \mu \mathrm{l}\right)$ & $241(196.5-284.5)$ & $247.5(216-290)$ & $0.157^{*}$ \\
\hline & RDW (\%) & $10.4(9.9-11.7)$ & $10.35(9.87-11.32)$ & $0.634^{*}$ \\
\hline & MPV (fL) & $7.9(7-9.2)$ & $7.85(6.6-8.82)$ & $0.453^{*}$ \\
\hline & NLR & $4.71(3-7.37)$ & $5(2.81-8.75)$ & $0.704^{*}$ \\
\hline & PLR & $113.63(87.51-156.86)$ & $125.2(92.06-174.93)$ & $0.138^{*}$ \\
\hline & CRP (mg/L) & $12.9(3-41)$ & $37(5-94.5)$ & $0.001^{*}$ \\
\hline & Bilirubin $(\mathrm{mg} / \mathrm{dL})$ & $0.3(0.2-0.6)$ & $0.4(0.2-0.72)$ & $0.103^{*}$ \\
\hline & AST (IU/L) & $19(15-24)$ & $20(15.75-26.5)$ & $0.134^{*}$ \\
\hline & ALT (IU/L) & $17(12-24.5)$ & $17.5(12-25)$ & $0.955^{*}$ \\
\hline & Albumin (g/dL) & $4.5(4.3-4.7)$ & $4.5(4.17-4.8)$ & $0.269^{*}$ \\
\hline Operation type & $\begin{array}{c}\text { Open } \\
\text { Laparoscopic }\end{array}$ & $\begin{array}{l}391(80 \%) \\
98(20 \%)\end{array}$ & $\begin{array}{c}67(90.5 \%) \\
7(9.5 \%)\end{array}$ & $0.029^{* *}$ \\
\hline $\begin{array}{l}\text { Presence of appendix } \\
\text { perforation }\end{array}$ & $\begin{array}{l}\text { None } \\
\text { Present }\end{array}$ & $\begin{array}{l}422(86.3 \%) \\
67(13.7 \%)\end{array}$ & $\begin{array}{l}50(67.6 \%) \\
24(32.4 \%)\end{array}$ & $<0.001^{* *}$ \\
\hline \multirow{4}{*}{$\begin{array}{l}\text { Histopathological } \\
\text { characteristics }\end{array}$} & Normal appendix & $20(4.1 \%)$ & $3(4.1 \%)$ & \multirow{4}{*}{$<0.001^{* *}$} \\
\hline & $\begin{array}{l}\text { Acute appendicitis or acute } \\
\text { phlegmonous appendicitis }\end{array}$ & $424(86.7 \%)$ & $49(66.2 \%)$ & \\
\hline & $\begin{array}{l}\text { Perforated or gangrenous } \\
\text { appendicitis }\end{array}$ & $41(8.4 \%)$ & $21(28.4 \%)$ & \\
\hline & Tumor or mucocele & $4(0.8 \%)$ & $1(1.4 \%)$ & \\
\hline \multicolumn{2}{|c|}{ Post-operative hospital stay (days) } & $2(1-2)$ & $2(1-5)$ & $0.004^{*}$ \\
\hline
\end{tabular}

\section{Discussion}

Acute appendicitis is more commonly observed in young adults aged between 10-30 years, and it is slightly more common in males, compared to females (8). The median age of both patient groups was around 30 years in our study. Out of the total number of patients, $314(55.8 \%)$ and $249(44.2 \%)$ cases were male and female, respectively. The appendix perforation can easily cause peritonitis. Therefore, surgical treatment is inevitable in patients diagnosed with acute appendicitis (9). Successful diagnosis is more easily achieved through technological advances in laboratory tests and radiological methods (10). The critical fact in acute appendicitis is to achieve a definite diagnosis and perform surgery at the right time before complications develop.

Although non-complicated appendicitis can be treated with appendectomy, perforation can cause life-threatening complications in some cases. The perforation detection rate in patients operated for acute appendicitis has been reported between 12\% and $36.6 \%$ (11-14). In our study, the perforated appendix rates were obtained at $13.7 \%$ and $32.4 \%$ in the Turkish and refugee patient groups, respectively. The perforation ratio in the Turkish patient group was compatible with the literature data; however, the perforation rate in the refugee patient group was high. It is believed that the primary cause of this finding is that refugee patients delay hospital application after the onset of the symptoms.

The increase in the number of leukocytes and neutrophils is an expected condition in acute appendicitis cases. According to available data, WBC is an important parameter for acute appendicitis diagnosis (15). However, it is not a specific marker, and the increase is noted in many inflammatory conditions. In a study conducted by Sevinç et al. (4), the mean WBC value was reported as $14.3 \pm 4.2$ in the acute appendicitis group and $15.8 \pm 4.9$ in the perforated appendicitis group. In our study, regardless of perforation, the mean WBC value in the Turkish patient group was determined at $13.6 \pm 4.04$, while it was $13.3 \pm 4.12$ in the refugee patient group. Many studies have reported that the number of neutrophils increases while the lymphocyte count decreases in acute appendicitis, and the increased neutrophil/lymphocyte ratio has a high sensitivity in diagnosis $(3-5,16)$.

In a study conducted by Yardımcl et al. (5), the mean NLR value was reported as $8.3 \pm 5.6$ in the phlegmonous appendicitis group and $10.6 \pm 6.4$ in the perforated appendicitis group. They stated that the cut-off value of NLR, sensitivity, and specificity were $7.95,78 \%$, and $67 \%$ for perforation or gangrenous appendicitis, respectively. In our study, median IQRs of the NLR values were 4.71 (range: $3-7.37$ ) and 5 (range: 2.81-8.75) respectively. Although the median 
NLR value was high in the refugee patient group, no statistically significant difference was found in this regard.

CRP is an acute-phase reactant and has been shown to increase later than leukocyte count in case of inflammation (14). Several studies reported the relationship between acute appendicitis and CRP elevation. Moreover, the specificity of CRP is higher in the presence of perforation $(7,14,17)$. In a study conducted by Özozan et al. (7), the mean CRP value was $11.76 \pm 8.91$ in the perforation group. Moreover, they determined CRP as a significant factor in predicting perforation in acute appendicitis.

In our study, the median IQR of the CRP value in the refugee patient group with a high perforation rate was $37 \mathrm{mg} / \mathrm{L}$ (5-94.5) and was statistically higher than that in the Turkish patient group. As can be observed, many studies in the literature have investigated hemogram and biochemical parameters that may be associated with acute appendicitis or perforated appendicitis. In our study, two different patient groups were demographically compared. Our current patients consisted of patients operated for non-complicated appendicitis or perforated appendicitis. Therefore, no statistically significant difference was found between hemogram and biochemical values other than CRP value between the two groups.

After the civil war that was started in Syria in 2011, approximately 420,000 Syrian refugees started living in our cities close to the border region (18). The number of Syrian refugees in Turkey is higher than that in other neighboring countries. All refugees face challenging living conditions worldwide. They experience many physical and psychological health problems. Despite these adverse conditions, all Syrian refugees have access to healthcare in our country free of charge. However, due to some factors, such as the effects of changing life conditions, unfavorable socio-economic conditions, and communication problems (language barrier), refugee patients may delay their hospital applications.

Complicated acute appendicitis is considered an indicator of a lack of healthcare access in children based on communication skills (19). It has been reported that immigrants have an increased risk of perforated/complicated appendicitis or unnecessary surgery for acute abdominal pain (20). Tatsiani et al. (20) reported that the perforation rate was $33.3 \%$ in immigrant patients, while it was $20.8 \%$ in local citizens. Liu et al. (21) also indicated that immigrants had a lower rate of healthcare use than other citizens; however, there was no difference in complicated appendicitis rates. In our study, the perforated appendix rate was $32.4 \%$ in the refugee patient group, and it was higher in the refugee patient group, compared to the Turkish patient group.

Regarding the limitation of the study, one can refer to the retrospective and observational design of the research. Moreover, there was a numerical difference between the patient groups, and this single-center study was conducted using a relatively limited number of patients. In addition, since there was no third healthy control group, the laboratory marker making a significant difference other than CRP could not be detected. There was also no data regarding the time between hospital application and symptom onset. The most important advantage of our study is that, in contrast to the design of many other studies in the literature, two different patient groups, who underwent appendectomy for acute appendicitis, were compared both demographically and socioculturally.

\section{Conclusion}

It is believed that the hospital application time was delayed due to the current socio-economic conditions and communication problems (language barrier) of refugee patients. Therefore, general surgery specialists in countries with intense refugee populations, such as Turkey, should consider the possibility of complicated appendicitis in refugee patients scheduled for surgery for acute appendicitis.

\section{Acknowledgments}

None

\section{Footnotes}

Authors' Contribution: Durmuş Ali Çetin: Study design, planning methodology, data collection, and writing; Mehmet Patmano: Patient follow-up and reporting, data collection, and literature review; Tufan Gümüş: Literature review, supervising, and reviewing the article; and Hasan Elkan: Patient follow-up and reporting, supervising, and reviewing the article.

Conflicts of Interest: There is no conflict of interest regarding the publication of the study.

Ethical Approval: This study was approved by the Local Ethics Committee of Harran University Medical Faculty Hospital, Şanlıurfa, Turkey (HRU/20.11.04).

Funding/ Support: None

Financial Disclosure: None

Informed Consent: As the study was designed retrospectively, the data were collected from the clinical archive.

\section{References}

1. Shogilev DJ, Duus N, Odom SR, Shapiro NI. Diagnosing appendicitis: evidence-based review of the diagnostic approach in 2014. West J Emerg Med. 2014;15:859-71. doi: 10.5811/westjem.2014.9.21568. [PubMed: 25493136].

2. Şenocak R, Kaymak Ș. Diagnostic accuracy of ultrasonography and scoring systems: The effects on the negative appendectomy rate and gender. Ulus Travma Acil Cerrahi Derg. 2020;26(2):306- 
13. doi: 10.14744/tites.2019.86717. [PubMed: 32185777$]$.

3. Çınar H, Aygün A, Derebey M, Tarım İA, Akalın Ç, Büyükakıncak $S$, et al. Significance of hemogram on diagnosis of acute appendicitis during pregnancy. Ulus Travma Acil Cerrahi Derg. 2018;24(5):423-8. doi: 10.5505/tjtes.2018.62753. [PubMed: 30394495].

4. Sevinç MM, Kınacı E, Çakar E, Bayrak S, Özakay A, Aren A, et al. Diagnostic value of basic laboratory parameters for simple and perforated acute appendicitis: an analysis of 3392 cases. Ulus Travma Acil Cerrahi Derg. 2016;22(2):155-62. doi: 10.5505/tjtes.2016.54388. [PubMed: 27193983].

5. Yardımcı S, Uğurlu MÜ, Coskun M, Attaallah W, Yeğen SC. Neutrophil-lymphocyte ratio and mean platelet volume can be a predictor for severity of acute appendicitis. Ulus Travma Acil Cerrahi Derg. 2016;22(2):163-8. doi: 10.5505/tites.2015.89346. [PubMed: 27193984].

6. İnan $\mathrm{M}$, Tulay $\mathrm{SH}$, Besim $\mathrm{H}$, Karakaya $\mathrm{J}$. The value of ultrasonography and its' comparison with Alvarado scoring system in acute appendicitis. Ulusal Cerrahi Derg. 2011;27(3):149-53. doi: 10.5097/1300-0705.ucd.1181-11.04.

7. Özozan ÖV, Vural V. High C-reactive protein level as a predictor for appendiceal perforation. Ulus Travma Acil Cerrahi Derg. 2020;26(1):63-6. doi: 10.14744/tjtes.2019.14799. [PubMed: 31942732].

8. Addiss DG, Shaffer N, Fowler BS, Tauxe RV. The epidemiology of appendicitis and appendectomy in the United States. Am J Epidemiol. 1990;132(5):910-25. doi: 10.1093/oxfordjournals. aje.a115734. [PubMed: 2239906].

9. Varadhan KK, Humes DJ, Neal KR, Lobo DN. Antibiotic therapy versus appendectomy for acute appendicitis: a meta-analysis. World J Surg. 2010;34(2):199-209. doi: 10.1007/s00268-0090343-5. [PubMed: 20041249].

10. Xiong B, Zhong B, Li Z, Zhou F, Hu R, Feng Z, et al. Diagnostic accuracy of non-contrast CT in detecting acute appendicitis: a meta-analysis of prospective studies. Am Surg. 2015;81(6):626-9. [PubMed: 26031278].

11. Flum DR, Morris A, Koepsell T, Dellinger EP. Has misdiagnosis of appendicitis decreased over time? A population-based analysis. JAMA. 2001;286(14):1748-53. doi: 10.1001/jama.286.14.1748. [PubMed: 11594900].

12. Steven LL, Alicia JW, Hung SH. Computed tomography and ultrasonography do not improve and may delay the diagnosis and treatment of acute appendicitis. Arch Surg. 2001;136(5):556-62. doi: 10.1001/archsurg.136.5.556. [PubMed: 11343547].

13. Anderson RE, Hugander A, Thulin AJ. Diagnostic accuracy and perforation rate in appendicitis: Association with age and sex of the patient and with appendectomy rate. Eur J Surg. 1992;158(1):37-41. [PubMed: 1348639].

14. Beltran MA, Mendez PE, Barrera RE, Contreras MA, Wilson CS, Cortes VJ et al. Is hyperbilirubinemia in appendicitis a better predictor of perforation than C-reactive protein? A prospective study. Indian J Surg. 2009;71(5):265-72. doi: 10.1007/s12262009-0074-8. [PubMed: 23133170].

15. Farooqui W, Pommergaard HC, Burcharth J, Eriksen JR. The diagnostic value of a panel of serological markers in acute appendicitis. Scand J Surg. 2015;104(2):72-8. doi: 10.1177/1457496914529273. [PubMed: 24737847].

16. Markar SR, Karthikesalingam A, Falzon A, Kan Y. The diagnostic value of neutrophil: lymphocyte ratio in adults with suspected acute appendicitis. Acta Chir Belg. 2010;110(5):5437. [PubMed: 21158332].

17. Panagiotopoulou IG, Parashar D, Lin R, Antonowicz S, Wells AD, Bajwa FM, et al. The diagnostic value of white cell count, Creactive protein and bilirubin in acute appendicitis and its complications. Ann R Coll Surg Engl. 2013;95(3):21521. doi: 10.1308/003588413X13511609957371. [PubMed: 23827295].

18. Turkey, inter-agency information sharing portal. Syria Regional Refugee Response. Available at: URL: http://data.unhcr.org/syrianrefugees/country.php; 2020.

19. Gadomski A, Jenkins P. Ruptured appendicitis among children as an indicator of access to care. Health Serv Res. 2001;36(1):129-42. [PubMed: 11324740].

20. Tatsioni A, Charchanti A, Kitsiou E, Ioannidis JP. Appendicectomies in Albanians in Greece: outcomes in a highly mobile immigrant patient population. BMC Health Serv Res. 2001;1(1):1-6. doi: 10.1186/1472-6963-1-5. [PubMed: 11472640].

21. Liu TL, Tsay JH, Chou YJ, Huang N. Comparison of the perforation rate for acute appendicitis between nationals and migrants in Taiwan, 1996-2001. Public Health. 2010; 124(10):565-72. doi: 10.1016/j.puhe.2010.05.009. [PubMed: 20719346]. 